\title{
The Basic Empathy Scale adapted to French middle childhood: Structure and development of empathy
}

\author{
Leila Bensalah $^{1}$ - Nicolas Stefaniak ${ }^{1}$ - Arnaud Carre ${ }^{2,3,4,5} \cdot$ Chrystel Besche-Richard $^{1}$
}

Published online: 30 September 2015

(C) Psychonomic Society, Inc. 2015

\begin{abstract}
We adapted the adult French version of the Basic Empathy Scale to French children aged 6-11 years, in order to probe the factorial structure underlying empathy. A total of 410 children (189 girls and 221 boys) were instructed to fill out the resulting Basic Empathy Scale in Children (BES-C). Results showed that, as in adulthood, the three-factor model of empathy (i.e., emotional contagion, cognitive empathy, and emotional disconnection) was more relevant than the oneand two-factor ones. This means that as early as 6 years of age, children's responses should reflect the same organization of the three components of empathy as those of adults. In line with the literature, cognitive empathy increased and emotional disconnection decreased in middle childhood, while emotional contagion remained stable. Moreover, girls exhibited greater emotional contagion than boys, with the reverse pattern being observed for emotional disconnection. No sex difference was found regarding cognitive empathy.
\end{abstract}

Keywords Empathy $\cdot$ Emotion $\cdot$ Emotion regulation $\cdot$ Child · Basic Empathy Scale (BES)

Leila Bensalah

leila.bensalah@univ-reims.fr

Department of Psychology, University of Reims, Reims, France

2 Université de Savoie Mont Blanc, LIPPC2S, EA4145, Chambéry F-73000, France

3 Mental Health and Public Health, Inserm, U1178, Paris F-75014, France

4 Université Paris Descartes, Paris F-75014, France

5 Université Paris Sud, Paris F-75014, France
A great many studies have explored empathy in childhood, but several issues remain unclear concerning its underlying components. In order to identify the components of empathy in childhood, we administered a simplified version of the Basic Empathy Scale in Adults (BES-A) (Carré, Stefaniak, D'Ambrosio, Bensalah, \& Besche-Richard, 2013), a French translation of the BES that has already been validated in French adults, to French children aged 6-11 years, to determine whether it is possible to replicate the three-factor structure of the BES. In other words, we set out to find evidence that, in accordance with the current view, the empathic response is subtended by a three-factor structure comprising emotional contagion, $\operatorname{cog}$ nitive empathy and emotional disconnection (Carré et al., 2013).

Emotional contagion (CONT) refers to an automatic replication of another person's emotion (Hatfield, Cacioppo, \& Rapson, 1993; Iacoboni \& Dapretto, 2006). Cognitive empathy (CE) is defined as the ability to understand and mentalize another person's affects (Decety \& Svetlova, 2012). Thus, CE is viewed as being subtended by a theory-of-mind process (Shamay-Tsoory, 2011). In adults, emotional disconnection (DIS) is seen as involving cognitive processes such as perspective taking and emotion regulation, to protect oneself from distress, pain, and an extreme emotional impact due to another person (Batson et al., 1987; Lamm, Batson, \& Decety, 2007).

\section{Tools for measuring empathy in middle childhood}

To date, four questionnaires have been used to investigate the processes that subtend empathy in middle childhood (Bryant, 1982; Garton \& Gringart, 2005; Litvack-Miller, McDouglas, \& Romney, 1997; Reid et al., 2013). Garton and Gringart's (2005) questionnaire was motivated by the study of the role of empathy in the efficiency of collaborative problem solving in school education. The other authors focused on assessing the 
link between empathy and prosocial behavior in either typical (Bryant, 1982; Litvack-Miller et al., 1997) or atypical (Reid et al., 2013) children.

Two of these questionnaires, used with children aged $7-$ 9 years or 7-11 years (Garton \& Gringart, 2005; LitvackMiller et al., 1997), are independent adaptations of the Interpersonal Reactivity Index (IRI; Davis, 1980), which encompasses perspective taking (PT; the ability to adopt another person's perspective), fantasy ( $\mathrm{F}$; the tendency to imagine oneself in the role of a fictional character), empathic concern (EC; the tendency to react with feelings of concern and compassion in the face of another person's distress), and personal distress (PD; the tendency to react to another person's distress with self-oriented feelings of distress and anxiety). The third questionnaire, designed for use with children aged 6-12 years, is the Index of Empathy (IE; Bryant, 1982), an adaptation of the Questionnaire Measure of Emotional Empathy (QMEE; Mehrabian \& Epstein, 1972), which treats emotional empathy as a vicarious emotional response to the emotion of another person. Finally, Reid and colleagues recently developed the Kids' Empathic Development Scale (KEDS; Reid et al., 2013). The KEDS measures empathy in 7- to 11-year-olds exposed to emotional stories, and considers three factors: an affective component relating to emotional inference, that is, the ability of children to take the place of another person and then to imagine what that person is feeling on the basis of situational and non-emotional cues; a cognitive component, referring to the explanations or justifications that children produce to explain their emotional inference; and a behavioral component that concerns adaptive behaviors in relation to the emotional scenario.

All four questionnaires have come in for strong criticism. First, none of them clearly delimit the boundaries of affective empathy. Jolliffe and Farrington (2006) underlined the confusion that exists between empathy and sympathy in both the IRI and the QMEE. Whereas empathy requires the individual to share the same perceived emotion as the other person, sympathy is defined as the appraisal of how one feels about another person's emotion (Eisenberg \& Strayer, 1987). This distinction is important for delimiting empathy (Decety, 2010, 2011a, b). Although Jolliffe and Farrington (2006) were talking about the adult versions of the IRI and QMEE, their concerns are probably just as relevant to the child versions of these questionnaires. Within the same factor, for instance, some items refer to affective empathy (e.g., Garton \& Gringart, 2005: "When people around me are nervous or worried, I get a bit scared and worried too"; Litvack-Miller et al., 1997: "When other people are feeling bad or are very upset, I feel scared"), while others should be regarded as probing sympathy (e.g., Garton \& Gringart, 2005: "I often feel worried about people that are not lucky as me, and feel sorry for them"; Litvack-Miller et al., 1997: "I feel sorry for other kids whose lives are not as good as mine"). Nor is the definition of affective empathy any clearer in the KEDS, as its affective component requires children to draw an emotional inference from a scenario that involves taking another person's perspective. This should therefore be viewed as testing theory-ofmind ability rather than affective empathy, which mainly concerns the sharing of emotions.

Second, cognitive empathy should specifically relate to the understanding of emotional situations or other people's emotional states, and not be confused either with the broader ability to adopt another person's perspective (Jolliffe \& Farrington, 2006), as it is in the IRI (which assesses the cognitive component of the PT factor), or with an affective theory-of-mind response, as it is in the KEDS, when children are asked to identify which emotion the target character should feel.

The third issue concerns the assessment of the behavioral component of empathy in the KEDS. This questionnaire presents emotional stories featuring a target character and a bystander. However, the behavioral component of these stories appears problematic, in that the questions concern both the target character's imminent behavior and the behavior that the bystander should display. In our opinion, however, only the bystander can exhibit empathic behavior. Thus, if a respondent cites the behavior of the target character, this should be regarded as a search for a solution to that character's own emotional feeling, which relates to emotion regulation strategies (i.e., the modulation of vicarious emotion; Decety \& Michalska, 2010).

The fourth argument concerns the way the IRI has been adapted to the middle childhood population. Although its four-factor structure (i.e., PT, F, EC, and PD) is preserved in Litvack-Miller et al.'s (1997) version, the fact that the number of items is reduced from 28 to 22 suggests that this adaptation does not totally match the adult model. In other words, if some of the items in this adaptation of the IRI, which exhibits good psychometric properties, needed to be removed, it suggests that they were not correctly understood by the children. The same criticism could be leveled at Garton and Gringart's (2005) version, where the number of items is reduced still further, to 18 . Moreover, their questionnaire has only a two-factor structure, probably owing to the authors' inappropriate use of principal component analysis rather than confirmatory factor analysis - a statistical choice that shows they were not guided by the model of the IRI. The consequence of this restructuring is that items that belonged to different factors in the original version of IRI are now grouped in the same one, such that one factor encompasses both personal distress and empathic concern items, and the other both personal distress and perspective-taking items.

Another important point concerns the fact that these adaptations appear to be unable to replicate at least three results reported in the literature. First, Davis and Franzoi's (1991) study showed that personal distress declines in adolescence, and one would expect a similar decline to be observed in younger children. As perspective taking and emotion regulation are enhanced in childhood, children should gradually 
become better able to protect themselves from distress (Lamm et al., 2007). Second, Surtees and Apperly (2012) found that perspective taking increases during the middle childhood period. However, no developmental change was observed in either of these factors in Litvack-Miller et al.'s (1997) version of the IRI. Finally, a gender difference in favor of girls aged 612 years is usually observed for affective empathy (e.g., Bryant, 1982), but the KEDS is surprisingly insensitive to this difference, suggesting that it may assess something other than what it is supposed to measure. It is therefore crucial that the structure of any instrument assessing the components that underpin empathy should be in accordance with the findings in the literature on childhood and adolescence.

\section{The current concept of the development of empathy}

According to Decety (2010, 2011a, b; Decety \& Svetlova, 2012), three elements are gradually built into the construct of empathy: affective arousal, emotional understanding, and emotion regulation. Affective arousal (which can be equated with CONT) emerges during infancy, and is an automatic component (bottom-up processing) that makes it possible to distinguish between different emotional stimuli (e.g., hostile vs. hospitable, appetitive vs. aversive) and to respond adequately to them, although there is no emotion regulation (Decety, 2010, 2011a, b). Emotional understanding, which emerges at the age of 2-3 years, develops in parallel with the theory-of-mind and executive abilities that allow children to dissociate and maintain two people's points of view (Decety, 2010, 2011a, b). Children's progress in emotional understanding is due to improvements both in making inferences about others' mental states and in attentional, memory, and inhibitory control abilities. We can assume that these abilities gradually enhance children's CE component. Emotion regulation skills develop throughout childhood and adolescence, gradually allowing children to control various aspects of their personality (top-down processing), such as emotion, affect, motivation, and urges. We can assume that the gradual mastery of emotion regulation across an extended period of childhood (e.g., McCoy \& Masters, 1985; Zimmer-Gembeck \& Skinner, 2011) contributes to a gradual increase in CE, as this response can be seen as the outcome of controlled empathy. However, when emotion regulation proves inadequate and an individual starts to experience personal distress in the face of another person's distress, a mechanism for protecting oneself against distress (Lamm, Batson, \& Decety, 2007) and/ or "an egoistic motivation to reduce one's own aversive arousal" is activated (Batson, Fultz, \& Schoenrade, 1987). This mechanism fits the DIS component.

Thus, when seeking to assess empathy, we should not ignore Decety's integrative approach (2010, 2011a;
Decety \& Svetlova, 2012) whereby empathy is a dynamic process fuelled by three different elements throughout childhood until adolescence. This approach allows us to understand how these elements give rise to the different empathic responses (i.e., CONT, CE, and DIS) people have to emotional situations. One example of this approach is our application of the BES-A (Carré et al., 2013), a French adaptation of the scale originally developed by Jolliffe and Farrington (2006), to middle childhood. Given that Carré et al.'s (2013) study suggested that the best factor structure of the BES-A is a three-factor one comprising CONT, CE, and DIS, it seemed logical to examine whether the three-factor model probed in adults is also the best structure for middle childhood. Another advantage of the BES is that this scale has been widely validated, both in Western cultures, with Slovak pre-adolescents (Cavojova, Sirota, \& Belovicova, 2012), French (D’Ambrosio, Olivier, Didon, \& Besche, 2009) and Italian (Albiero, Matricardi, Speltri, \& Toso, 2009) adolescents, and French adults (Carré et al., 2013), and in Eastern cultures, with Chinese adolescents (Geng, Xia, \& Qin, 2012; Li, Lv, Liu, \& Zhong, 2011).

In the light of these arguments, we set out to examine the structure underlying empathy in middle childhood on the basis of the three-factor structure of the BES, and track the development of these three components across this age range in order to check that it was in accordance with previous findings. We reasoned that studying these two aspects (i.e., the structure of empathy and the development of its components) would contribute to the development of a tool that might be better adapted to the study of empathy in middle childhood.

\section{The development of the three components of empathy}

Several predictions could be made, based on previous findings concerning the development of the different components of empathy. First, we predicted that the CE response would increase, as previously shown in two developmental studies (Hughes, Tingle, \& Sawin, 1981; Strayer, 1993) and one parental report study (Dadds et al., 2008). This prediction was also supported by several studies in childhood and adolescence that examined what can be regarded as a cognitive component of empathy, in that it refers to an emotional inference triggered by an emotional event experienced by a character. These studies showed that this ability becomes more efficient between 8 and 12 years of age (Choudhury, Blakemore, \& Charman, 2006) and continues to improve between the ages of $12-13$ and 19 years (Keulers et al., 2010; Van der Graaff et al., 
2014; Vetter et al., 2013). By contrast, extrapolating from Davis and Franzoi's (1991) study with adolescents, we assumed that the DIS response would decline. Given that perspective taking and emotion regulation develop during childhood (Batson et al., 1987; Lamm et al., 2007), we hypothesized that children gradually become able to use these processes, thus allowing them to reduce the impact on their emotional distress. It was not clear whether the CONT response would change, as the results are divergent. Some studies have demonstrated that emotion sharing increases across childhood (Knudson \& Kagan, 1982; Strayer, 1993) and early adolescence, between 13 and 16 years of age (Mestre, Samper, Frias, \& Tur, 2009), others have shown that this component remains stable (Dadds et al., 2008; Hughes et al., 1981), while yet others have found that affective empathy increases during childhood, stabilizing in early adolescence for girls and more or less leveling off for boys between 7 and 14 years of age (Lam, Solmeyer, \& McHale, 2012). Thus, the study of how these different components develop should bring new evidence to light and allow us to clarify the contradictory results observed in previous studies.

\section{Aims of the current study}

The primary aim of our study was to determine whether the three-factor structure of the original BES-A for French adults (Carré et al., 2013) is shared by its middle childhood version, the Basic Empathy Scale in Children (BES-C). To achieve this aim, we planned to run factor analyses to examine several possible factor structures $(1,2$, or 3 factors), as has been proposed in previous studies (Carré et al., 2013). A secondary aim was to produce new evidence in support of the threefactor structure, by showing that any changes in each of these factors were in accordance with previous findings: we predicted that there would be an increase in CE and a decrease in DIS, but no prediction could be made concerning CONT. Moreover, we expected to see the same gender differences as those observed in Carré et al. (2013), with higher DIS in boys than in girls, and higher CONT in girls than in boys. No difference was expected concerning CE. Finally, in order to ensure that responses to the BES-C were not biased, we decided to test the children on a social desirability scale. This study would allow us to both resolve the inconsistency of previous findings concerning the structure underpinning empathy, and build on the few existing results concerning the development of its three components.

\section{Method}

\section{Participants}

Children were recruited from public schools by sending a consent form to all the parents. Those whose parents gave their written informed consent were included in the study. We contacted a total of 450 French families and recruited 410 schoolchildren (90\% inclusion rate; 189 girls and 221 boys) aged between 6 and 11 years (range $=75-142$ months, mean $=105$ months, standard deviation $(S D)=17.36)$, as follows: 59 children aged 6 years, 80 children aged 7 years, 99 children aged 8 years, 72 children aged 9 years, 78 children aged 10 years, and 22 children aged 11 years. They were in the five years of elementary education and attended public schools in a middle-class district of Reims (France). This study was conducted in accordance with the Declaration of Helsinki.

In order to determine whether our adaptation of the BES-A, the BES-C, assessed the same components as the adult version in principle, 173 healthy young adults were also included in the study. These participants had initially taken part in the validation of the BES-A (Carré et al., 2013), and were among the 265 participants who agreed to complete the BES-A twice in a row, with a mean test-retest interval of 7 weeks. At both these sessions (test and retest), a self-report questionnaire was administered to identify past or present psychopathological markers (i.e., depression, anxiety disorders, neurological diseases, addiction). It should be noted that of the 173 healthy participants who agreed to complete the BES-C, 43 participants had to be excluded from the analyses, owing to current or previous psychopathological disorders. Participation in the BES-C was optional at the end of the BES-A retest session, after completing other scales included in the validation (i.e., alexithymia, state and trait anxiety, emotional consciousness, or another measure of empathy such as the IRI). Concerning the final sample of 130 healthy students who completed the BES-C, $80 \%$ were women $(n=104$; mean age $=19.12$ years, $S D=1.18)$. The men's mean age was 19.61 years $(S D=1.42)$.

\section{Basic Empathy Scale in Children (BES-C)}

The BES-C was an adaptation for French children of the French adult version (BES-A; Carré et al., 2013) of a 20item scale developed by Jolliffe and Farrington (2006). All the items of the BES-A were modified so that they would be understood by all the children in the sample (aged 6-12 years). Children rated each of these items on a 5-point Likert-like scale (1-5) that had also been adapted to their level of understanding. In order to facilitate the rating process, the Likert 
scale featured two smiling faces (meaning the two characters agreed) on the right (equivalent to Totally agree in the adult version), and a smiling face associated with a sad face (meaning the two characters disagreed) on the left (equivalent to Totally disagree in the adult version). Lastly, in accordance with findings in the literature (Feshbach \& Roe, 1968; Findlay, Girardi, \& Coplan, 2006; Knudson \& Kagan, 1982), two versions were created, one for girls and one for boys, in order to facilitate the children's comprehension and responses. Feshbach and Roe's (1968) study showed that gender similarity between the child and the target character improves recognition of the affective state. Knudson and Kagan (1982) also used this principle in a questionnaire probing prosocial behavior. This approach is consistent with the gender segregation that occurs in childhood (e.g., Hoffmann, 2001; Wu, Zhou, Wei, \& Bao, 2013). In other words, one major difference between the adult and child versions is that we introduced gender into the items in the French version for children. Concretely, half the items featured same-gender friends (e.g., Items 2 and 3 in Appendix 1) and half were formulated in a more general way (e.g., Items 9 and 14 in Appendix 1), in accordance with the adult version. There were no cross-gender items. Girls filled out the same-gender (for girls) and general items of the questionnaire, and boys filled out the same-gender (for boys) and general items of the questionnaire. Like the original BES and the BES-A, the BES-C included eight reversed items, and scores could range from 20 (lack of empathy) to 100 (high degree of empathy). The questionnaire was filled in collectively in classrooms. The design consisted in the experimenter reading out the instructions to the children about how to rate each item on the Likert scale. The experimenter could answer any questions the children might raise concerning the items in the questionnaire, for instance, if they did not understand an item or felt two items were very similar. This questionnaire was followed by the social desirability scale (Coopersmith, 1984). After a mean interval of 1 month, the BES-C was once again administered to all the children in the same conditions (i.e., version of the scale matching the child's gender).

\section{Social desirability scale}

In order to verify how many of the children's responses were motivated by a desire to please, we adapted the lie subscale of the self-esteem scale designed by Coopersmith (1984) to our middle childhood population. Children had to rate eight items ("I never feel worried," "I always do what I'm supposed to," "I never feel happy," "I like all the people I know," "People never criticize me," "I never feel cowed in the presence of an adult," "I always speak the truth," "I always know what to say to other people") by responding either "It is true" (T) (scored 0 ) or "It is false" (F) (scored 1) for her/him. We did not expect to find any significant link between scores on this subscale and scores on the BES-C.

\section{Results}

\section{Psychometric properties of the BES-C}

In order to determine whether the BES-C assessed the same components as the BES-A in principle, we administered the BES-C to 130 young adults (mean age $=19.15$ years, $S D=$ 1.17) drawn from Carré et al.'s (2013) sample. We performed correlations between the three factors of the BES-A and their corresponding factors in the children's version. These analyses revealed strong correlations: $.81\left(r^{2}=.65, p<.001\right)$ for CONT; $.70\left(r^{2}=.49, p<.001\right)$ for CE; and $.74\left(r^{2}=.55\right.$, $p<.001)$ for DIS.

Given that these results supported our assumption that the two French versions of the BES (BES-A and BES-C) assessed the same components, we set out to validate the factor structure with a sample of children. We ran a confirmatory factor analysis on the polychoric correlations, using the method of diagonally weighted least-squares parameter estimation to assess the factor structure of the BES-C with our sample of French-speaking children. This analysis was performed on the first dataset (i.e., data collected during the test phase). We tested three different factor solutions that had previously been tested in French adults (Carré et al., 2013), namely a single-factor solution, a two-factor solution, and a threefactor solution, which was the one retained by Carré et al. (2013). When performing the analyses, we assumed that the residual errors were uncorrelated.

Concerning the one-factor solution, analysis revealed that the model fitted the data, $\chi^{2}(170)=539.84, p<.001$, root mean square error of approximation (RMSEA) $=.073,90 \%$ confidence interval (CI; .066-.80), goodness of fit index $(\mathrm{GFI})=.92$, adjusted GFI $(\mathrm{AGFI})=.90$. These different indices revealed a reasonably good fit between the model and the data, for although the $\chi^{2}$ value was more than three times the degree of freedom, the RMSEA was less than .08 , and both the GFI and AGFI were greater than or equal to 0.90 .

According to the two-factor model of the BES (D'Ambrosio et al., 2009; Jolliffe \& Farrington, 2006), nine items probe CE (Items 3, 6, 9, 10, 12, 14, 16, 19, 20) and 11 items probe affective empathy (Items 1, 2, 4, 5, 7, 8, 11, 13, $15,17,18)$. The different adjustment criteria for the two-factor solution suggested that this model accounted for the data better than the one-factor solution, $\chi^{2}(169)=498.89, p<.001$, RMSEA $=.069,90 \%$ CI $.062-.076$, GFI $=.92$, AGFI $=.90$.

Finally, according to the three-factor structure of the BESA, six items correspond to the CONT factor (Items 2, 4, 5, 11, 15, and 17), eight items concern the $\mathrm{CE}$ factor (Items 3, 6, 9, $10,12,14,16$, and 20), and six items refer to the DIS factor 
Fig. 1 Factor loadings of the three-factor model of the Basic Empathy Scale (BES) in Children. Note. CONT = emotional contagion, $\mathrm{CE}=$ cognitive empathy, DIS = emotional disconnection

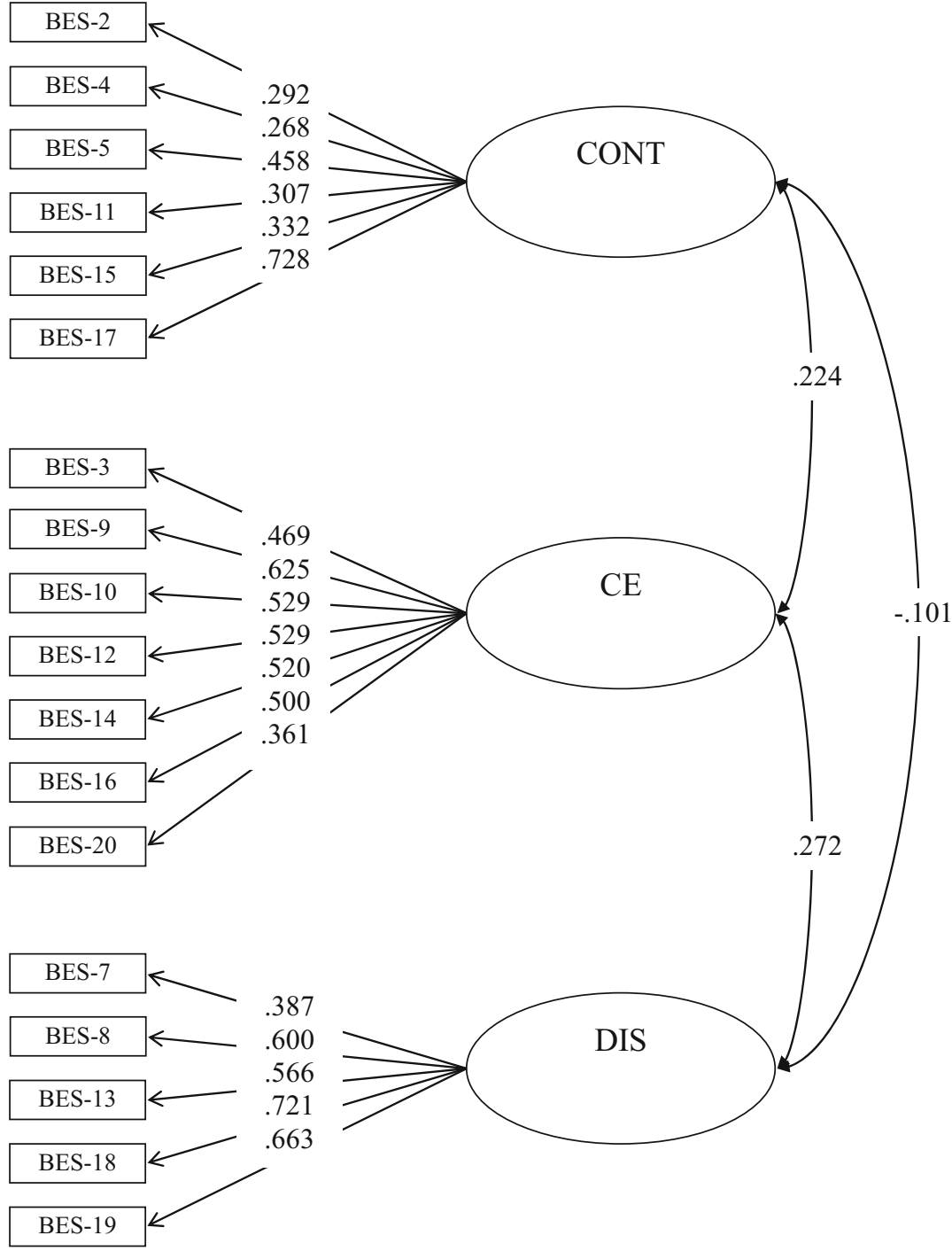

(see Appendix 1). The distribution of the items according to the three factors is provided in Appendix 2. The different adjustment criteria showed that this was the best solution, $\chi^{2}(167)=299.41, p<.001$, RMSEA $=$ $.044,90 \%$ CI .036-.052, GFI $=.95$, AGFI $=.93$. However, although the fit indices were good for the three-factor solution, two items had low loadings: Item 1 (.16) and Item 6 (.05) (see Appendix 1). Given that error covariance did not help to improve their loadings, we decided to delete both these items. These deletions improved the model: $\chi^{2}(132)=233.12, p<.001$, RMSEA $=$ $.043,90 \%$ CI $.034-.052, \mathrm{GFI}=.95, \mathrm{AGFI}=.94$. The loadings of this model are summarized in Fig. 1.

In order to determine the internal consistency of the BES$\mathrm{C}$, we computed Cronbach's alpha for each factor in the threefactor model on the polychoric correlations, in accordance with Gadermann, Guhn, and Zumbo's recommendation (2012). Cronbach's alpha was .66 for CE, .56 for CONT, and .68 for DIS. Finally, the alpha for the whole scale was 0.73. The individual item-total correlations for the three-factor structure are provided in Appendix 2.

The fact that DIS and CONT were only weakly correlated $\left(r=-.101, r^{2}=.01 p=.04\right)$ lends support to the notion that these two factors assessed two independent components. The correlations between CONT and CE $\left(r=.224, r^{2}=.05 p<\right.$ $.001)$ and between CE and DIS $\left(r=.272, r^{2}=.074 p<.001\right)$ were stronger, but remained fundamentally weak, suggesting that these components could also be regarded as independent.

Finally, concerning the correlation between the desirability scale and the three-factor model, results showed that the desirability scale did not correlate with CE $\left(r=.017, r^{2}<.001\right.$, $p>.05$ ), and was negatively correlated with both CONT $\left(r=-.126, r^{2}=.16, p=.01\right)$ and DIS $\left(r=-.191, r^{2}=.036\right.$, $p=.0001)$. The absence of a correlation with CE means that this factor was not correlated with a desirability bias, unlike CONT and DIS. 


\section{Test-retest reliability}

We also analyzed test-retest reliability. After a mean interval of 1 month, all the children were tested again in the same collective conditions. The correlations between test and retest were analyzed for each of the different factors. The correlations were $r=.54, r^{2}=.294, p<.001$ between the two CE scores, $r=.60$, $r^{2}=.36, p<.001$ between the two CONT scores, and $r=.58$, $r^{2}=.34, p<.001$ between the two DIS scores.

\section{Changes in the three factors as a function of age and gender}

First, in order to determine whether age (in months) and gender had an impact on $\mathrm{CE}$, we performed multiple regression analyses on the CE score derived from the first dataset. In order to avoid false discovery, we also performed robust analyses (i.e., adjusted bootstrap percentile on regression betas; Wilcox, 2005), and excluded influential participants from the analyses (i.e., those for whom Cook's distance was above n/4, i.e., 0.01, as suggested by Bollen \& Jackman, 1990). Results revealed that this model was significant, $F(2,396)=13.64, p<.001$, $R^{2}=0.064$. The CE score was found to be influenced by age, but not by gender. These results are summarized in Table 1 .

We performed the same analysis on the DIS score. Results revealed that this model was significant, $F(2,396)=12.675, p<$ $.001, R^{2}=0.060$. As before, the DIS score was influenced by age, but not by gender. These results are summarized in Table 2 .

Finally, we ran this analysis on the CONT score. Results revealed that this model was significant, $F(2,388)=25.82, p$ $<.001, R^{2}=0.117$. The CONT score was influenced by gender, with girls displaying a higher level than boys, but not by age. These results are summarized in Table 3.

\section{Discussion}

This study was designed to examine the structure that underpins empathy in middle childhood. In order to achieve this

Table 1 Summary of the regression analysis of the effect of age on cognitive empathy

\begin{tabular}{llllrc}
\hline & $\beta^{\mathrm{a}}$ & $\mathrm{b}(\mathrm{BCa} \mathrm{CI})^{\mathrm{b}}$ & $\Delta \mathrm{R}^{2 \mathrm{c}}$ & $t^{\mathrm{d}}$ & $p^{\mathrm{e}}$ \\
\hline Gender & 0.04 & $0.37(-0.49-1.60)$ & $<.001$ & .78 & .43 \\
Age & 0.25 & $0.07(0.042-0.100)$ & 0.06 & 5.21 & $<.001$ \\
\hline
\end{tabular}

${ }^{\text {a }}$ Standardized regression coefficient (beta).

${ }^{\mathrm{b}}$ Regression coefficient (b) and Confidence Interval based on the Bias-Corrected and accelerated (BCa) bootstrap

${ }^{\mathrm{c}}$ The variance explained by the variable at each regression step

${ }^{\mathrm{d}} t$ value of the beta coefficient

${ }^{\mathrm{e}} p$ value of the beta coefficient
Table 2 Summary of the regression analysis of the effect of age on disconnection

\begin{tabular}{llclll}
\hline & $\beta^{\mathrm{a}}$ & $\mathrm{b}(\mathrm{BCa} \mathrm{CI})^{\mathrm{b}}$ & $\Delta \mathrm{R}^{2 \mathrm{c}}$ & $t^{\mathrm{d}}$ & $p^{\mathrm{e}}$ \\
\hline Gender & 0.18 & $1.77(0.522-2.473)$ & $<.028$ & 3.66 & $<.001$ \\
Age & 0.18 & $0.05(0.0239-0.0773)$ & 0.031 & 3.65 & $<.001$ \\
\hline
\end{tabular}

${ }^{\mathrm{a}}$ Standardized regression coefficient (beta)

${ }^{\mathrm{b}}$ Regression coefficient (b) and Confidence Interval based on the Bias-Corrected and accelerated (BCa) bootstrap

${ }^{\mathrm{c}}$ The variance explained by the variable at each regression step

${ }^{\mathrm{d}} t$ value of the beta coefficient

${ }^{\mathrm{e}} p$ value of the beta coefficient

aim, we validated a version of the BES (Jolliffe \& Farrington, 2006) adapted for French children (BES-C), based on the BES-A (Carré et al., 2013). As in Carré et al.'s study, we then tested one-, two-, and three-factor models. Interestingly, mirroring Carré et al.'s (2013) results in adults, our confirmatory factor analyses showed that the three-factor model fitted the data best and was therefore the most appropriate structure for probing the components that underpin empathy in children. This finding suggests that, in middle childhood, possible reactions to an emotional scenario featuring another person can be divided into three distinct categories: emotional contagion, cognitive empathy, and emotional disconnection. Emotional contagion refers to a response where the child may overstep the limits of what $\mathrm{s} / \mathrm{he}$ is able to bear and thus be overwhelmed by the other person's emotion (Decety, 2010, 2011a, b). Cognitive empathy refers to a controlled response to an emotional scenario. This response should be viewed as one that maintains a sufficient distance from the emotional scenario for the individual to be involved, but not overwhelmed (Decety \& Svetlova, 2012). Emotional disconnection corresponds to a response characterized by insufficient emotion regulation, leading to personal distress. This distress triggers a self-protection response (Lamm et al., 2007) and/or "an egoistic motivation to reduce one's own aversive arousal" (Batson et al., 1987). The fact that these three responses are the same as those observed in adults could

Table 3 Summary of the regression analysis of the effect of age on contagion

\begin{tabular}{lrrrrl}
\hline & \multicolumn{1}{l}{$\beta^{\mathrm{a}}$} & $\mathrm{b}(\mathrm{BCa} \mathrm{CI})^{\mathrm{b}}$ & \multicolumn{1}{c}{$\Delta \mathrm{R}^{2 \mathrm{c}}$} & \multicolumn{1}{l}{$t^{\mathrm{d}}$} & $p^{\mathrm{e}}$ \\
\hline Gender & 0.34 & $2.96(1.90-3.68)$ & .117 & 7.12 & $<.001$ \\
Age & -0.02 & $-0.006(-0.05-0.00)$ & $<.001$ & -0.53 & $<.60$ \\
\hline
\end{tabular}

${ }^{\text {a }}$ Standardized regression coefficient (beta)

${ }^{\mathrm{b}}$ Regression coefficient (b) and Confidence Interval based on the Bias-Corrected and accelerated (BCa) bootstrap

${ }^{\mathrm{c}}$ The variance explained by the variable at each regression step

${ }^{\mathrm{d}} t$ value of the beta coefficient

${ }^{\mathrm{e}} p$ value of the beta coefficient 
mean that the responses of children as young as 6 years reflect the same organization of the three components of empathy as those of their elders. However, it does not mean that their responses are necessarily sustained by the same psychological mechanisms as in adulthood. Childhood is a period of change, as suggested by Decety $(2010,2011 \mathrm{a}, \mathrm{b}$; Decety \& Svetlova, 2012), who claims that children's emotional understanding and emotion regulation abilities gradually increase until adolescence (McCoy \& Masters, 1985; Zimmer-Gembeck \& Skinner, 2011), as they access ever higher levels of theory of mind (Philpott et al., 2013) and executive functioning (Brocki $\&$ Bohlin, 2004). The development of these different abilities could influence the types of responses that are observed. Future research will need to explore further the relationship between these specific abilities and the development of each component of empathy across this period.

To support this three-factor model of empathy, we looked at the development of these factors and compared our results with previous findings. As expected, results showed that cognitive empathy responses increased between 6 and 11 years, while emotional disconnection responses decreased. There was no change in emotional contagion responses. The increase in cognitive empathy confirmed previous findings (Hughes et al., 1981; Dadds et al., 2008; Strayer, 1993). This could be due to enhanced understanding of emotional scenarios that draw on the theory of mind, executive functions, and emotional regulation all abilities that are known to develop across this period. More specifically, cognitive empathy could depend on the cognitive abilities (i.e., theory of mind and executive functions) that allow children to adopt the perspective of the other person involved in the emotional scenario instead of their own (Decety, 2010, 2011a, b). The increase in CE also indicates that children can adequately regulate their own emotions, thus avoiding being overwhelmed with emotion. The decrease in emotional disconnection was also consistent with previous results (Davis \& Franzoi, 1991). Better mastery of cognitive abilities (i.e., theory of mind and executive functions), and improved emotion regulation probably help to reduce emotional disconnection, even if it remains a suitable response in some specific circumstances. For instance, in some situations where children would be greatly affected by the distress of someone they did not know, DIS allows them to reduce their own distress by triggering a selfprotection reaction. There was no significant change in emotional contagion in middle childhood, thus supporting previous findings indicating that this response remains stable (Dadds et al., 2008; Hughes et al., 1981). Thus, even if it does not change during this period, CONT still constitutes a response that children can use in many of the emotional situations they encounter in everyday life. Children in middle childhood spend a lot of their time in school, meaning that they are permanently exposed to potential emotional situations involving not just their classmates but also other people outside school. When socializing with other children, they may find themselves in emotional situations that can lead to CONT if one of their friends is in distress or is treated unfairly or bullied. In these situations, they continue to share the other child's emotion until they become overwhelmed by it, rather than controlling it, owing to the suddenness of this reaction (e.g., in unfair situations).

In line with Carré et al.'s (2013) findings in adults, our results indicated that girls and boys behaved similarly with regard to cognitive empathy. The fact that boys and girls could not be differentiated on this component suggests that its development follows the same course regardless of gender. This is consistent with reports of only minor differences in perspective taking between adolescent girls and boys aged 13-14 to 17-18 years (Davis \& Franzoi, 1991; Van der Graaff et al., 2014), although this gender difference would appear to increase at the end of adolescence (Van der Graaff et al., 2014). By contrast, girls exhibited significantly more emotional contagion than boys, while boys displayed more emotional disconnection than girls. Thus, girls are more often overcome by emotion (i.e., bottomup processing), while boys become emotionally disconnected (i.e., top-down processing), and are thus able to protect themselves when exposed to an emotional scenario.

Concerning the links between the social desirability scale and the three components of empathy, results showed that CONT and DIS were impacted by desirability $(r=-.126$ and $r=-.191$, respectively), although this impact was weak (1.59\% and $3.65 \%$ of variance, respectively). This could mean that when a person is overwhelmed with emotion (CONT) or when $\mathrm{s} / \mathrm{he}$ is disconnected from the emotional scenario (DIS), this can be negatively viewed by others, and therefore influence their empathic responses - or at least the evocation of these responses. This bias was also observed in Litvack-Miller et al.'s (1997) study. Conversely, the fact that the CE was not impacted by social desirability could indicate that this empathic response creates an adequate emotional distance, respecting the social norm of how to behave in emotional situations.

The present study revealed coherence between the threefactor structure of empathy in adults and that in children. Although the three components of empathy followed the developmental trajectories reported in the literature, the present study had three main limitations. First, Cronbach's alphas were below the usual standards, particularly for emotional contagion (.56). One possible explanation is that younger children find it difficult to remain consistent across items, possibly because they misunderstand certain items, as was the case in Litvack-Miller et al.'s (1997) study. This finding is corroborated by Bryant (1982), who also found quite a low alpha for the younger children (i.e., .54 for 6-year-olds) and a higher value for the older ones (i.e., .79 for 12 -year-olds). It is also possible that children may labor under the misapprehension that if similar questions are asked several times, they should give different responses (e.g., Goodman \& Quas, 2008). Finally, the small number of items probing CONT could partly explain this problem, as Cronbach's alpha is sensitive to the number of items, and increases when the 
number of items increases (Cortina, 1993). The fact that Cronbach's alpha was satisfactory for the whole scale (.73) suggests that the statistical properties of Cronbach's alpha at least partly explained our results.

Second, the current study lacked external validity measures, even if the strong correlations between the BES-C and the BES$\mathrm{A}$ in the adult sample (.81 for CONT, .70 for $\mathrm{CE}$, and .74 for DIS) support our scale's external validity. Further studies measuring external validity would allow us to confirm previous findings whereby empathy is positively related to prosocial behaviors (e.g., Schonert-Reichl et al., 2012) and moral reasoning (e.g., Decety \& Michalska, 2010; Eisenberg et al., 1987; Humphries et al., 2000), and negatively related to antisocial behaviors (e.g., Garaigordobil, 2009; Munoz et al., 2011; Qualter \& Padget, 2011; Yeo et al., 2011). Third, the fact that empathy is related to sympathy (e.g., Decety \& Michalska, 2010) and that both are linked to behavioral helping (e.g., Eisenberg et al., 1987) suggests that future research should be broadened to study the link between the two concepts.

Finally, the BES-C could prove useful for studying empathy from a new perspective, particularly in children who display impaired empathy, such as those with autism spectrum disorder (e.g., Bons et al., 2013; Schwenck et al., 2012). This would extend the current literature on empathy in middle childhood. Future studies should explore how our adaptation of the BES could be used in other languages and cultures, not least because it would tell us whether empathy has a universal structure.

The results of the current study underline the weaknesses of the empathy scales that have been used in children up to now. Indeed, it was in order to avoid the biases we uncovered in other scales that we developed the BES-C. Although we noted a weakness in internal consistency, particularly for the CONT component, we showed that the BES-C is adapted to French children and corresponds to what is known about empathy, and that interestingly its components change in line with descriptions in the literature. Finally, the three-factor structure observed in the BES-C can be regarded as corresponding to the structure observed in the BES-A. It therefore represents a possible alternative means of exploring empathy in middle childhood.

\section{Appendix 1}

Items in the French version (for girls) and the English translation:

Item 1: « La joie de mes copines ne me rend pas forcément joyeuse » [The happiness of my (female) friends doesn't necessarily make me feel happy]

Item 2: «Après avoir été avec une copine qui est triste, je me sens triste » [When I've been with a (female) friend who's sad, I feel sad]
Item 3: « Je peux comprendre la joie d'une copine quand tout va bien pour elle » [I can understand the happiness a (female) friend feels when everything's going right for her]

Item 4: « Dans un film, quand le garçon ou la fille a peur, j'ai peur aussi » [When a girl or a boy is afraid in a film, I'm afraid, too]

Item 5: « Je suis facilement contente quand les autres sont contents » [I generally feel happy when others are happy] Item 6: « J'ai du mal à savoir quand mes camarades ont peur » [I find it hard to know when my friends are scared] Item 7: « Je ne suis pas triste quand je vois une personne triste » [I'm not sad when I see someone who's sad] Item 8: «Les problèmes des autres ne m'inquiètent pas du tout » [Other people's problems don't bother me at all] Item 9: «Quand quelqu'un se sent triste, je peux le comprendre » [When someone feels sad, I can understand them]

Item 10: «Généralement, j'arrive à savoir que mes copines ont peur » [I can usually tell when my (female) friends are scared]

Item 11: « Souvent, je me sens triste quand je regarde des choses ou des films tristes » [I often feel sad when I see sad things or watch sad films]

Item 12: «Souvent, je peux comprendre comment les gens se sentent même s'ils ne me l'ont pas dit » [I can often understand how people feel even when they don't tell me]

Item 13: "Voir une personne se mettre en colère ne me fait rien » [When I see someone who's angry I'm not scared]

Item 14: «Habituellement, je sais quand les gens sont joyeux » [I generally know when people are happy]

Item 15: « J'ai tendance à avoir peur quand je suis avec des copines qui ont peur » [I tend to be afraid when I'm with female) friends who are afraid]

Item 16: « Généralement, je me rends vite compte quand une copine est en colère » [It generally doesn't take me long to realize a (female) friend is angry]

Item 17: «Je me sens souvent comme mes camarades: joyeux quand ils sont joyeux ou tristes quand ils sont tristes » [I often feel the same way as my classmates: happy when they're happy and sad when they're feeling sad]

Item 18: "Cela ne me fait rien de voir qu'une de mes copines est triste » [I don't feel anything when I see that one of my (female) friends is sad]

Item 19: « Je ne fais généralement pas attention aux soucis de mes copines » [I don't generally pay any attention to my (female) friends' worries]

Item 20: « J'ai du mal à comprendre quand mes copines sont contentes » [I find it hard to understand when my (female) friends are happy] 


\section{Appendix 2}

Table 4 Item-total correlations

\begin{tabular}{llll}
\hline Item & CONT & CE & DIS \\
\hline 1 & & & deleted \\
2 & .14 & & \\
3 & & .28 & \\
4 & .28 & & \\
5 & .22 & & .29 \\
6 & & deleted & \\
7 & & & .39 \\
8 & & & \\
9 & & .40 & .42 \\
10 & & .41 & .42 \\
11 & .25 & & \\
12 & & .33 & \\
13 & & & \\
14 & & .37 & \\
15 & .29 & & \\
16 & & .33 & \\
17 & .29 & & \\
18 & & & \\
19 & & & \\
20 & & .9 & \\
\hline
\end{tabular}

Note. CONT $=$ emotional contagion, $\mathrm{CE}=$ cognitive empathy, DIS = emotional disconnection

\section{References}

Albiero, P., Matricardi, G., Speltri, D., \& Toso, D. (2009). The assessment of empathy in adolescence: A contribution to the Italian validation of the "Basic Empathy Scale". Journal of Adolescence, 32, 393-408. doi:10.1016/j.adolescence.2008.01.001

Batson, C. D., Fultz, J., \& Schoenrade, P. A. (1987). Distress and empathy: Two qualitatively distinct vicarious emotions with different motivational consequences. Journal of Personality, 55, 19-39. doi:10. 1111/j.1467-6494.1987.tb00426.x

Bollen, K. A., \& Jackman, R. W. (1990). Regression diagnostics: An expository treatment of outliers and influential cases. In J. Fox \& J. S. Long (Eds.), Modern methods of data analysis (pp. 257-291). Newbury Park, CA: Sage Publications.

Bons, D., van den Broek, E., Scheepers, F., Herpers, P., Rommelse, N., \& Buitelaar, J. K. (2013). Motor, emotional, and cognitive empathy in children and adolescents with autism spectrum disorder and conduct disorder. Journal of Abnormal Child Psychology, 41, 425-443. doi: 10.1007/s10802-012-9689-5

Brocki, K. C., \& Bohlin, G. (2004). Executive functions in children aged 6 to 13: A dimensional and developmental study. Developmental Neuropsychology, 26, 571-593. doi:10.1207/s15326942dn2602 3

Bryant, B. K. (1982). An index of empathy for children and adolescents. Child Development, 53, 413-425. doi:10.2307/1128984

Carré, A., Stefaniak, N., D'Ambrosio, F., Bensalah, L., \& BescheRichard, C. (2013). The Basic Empathy Scale in adults (BES-A):

Factor structure of a revised form. Psychological Assessment, 25, 679-691. doi:10.1037/a0032297

Cavojova, V., Sirota, M., \& Belovicova, Z. (2012). Slovak validation of the Basic Empathy Scale in pre-adolescents. Studia Psychologica, 54, 195-208.

Choudhury, S., Blakemore, S.-J., \& Charman, T. (2006). Social cognitive development during adolescence. Social Cognitive and Affective Neurosciences, 1, 165-174.

Coopersmith, S. (1984). Manuel: Inventaire d'estime de soi de S. Coopersmith, SE.I. Paris: Les Editions du Centre de Psychologie Appliquée.

Cortina, J. M. (1993). What is coefficient alpha? An examination of theory and applications. Journal of Applied Psychology, 78, 98104. doi:10.1037/0021-9010.78.1.98

D'Ambrosio, F., Olivier, M., Didon, D., \& Besche, C. (2009). The basic empathy scale: A French validation of a measure of empathy in youth. Personality and Individual Differences, 46, 160-165. doi: 10.1016/j.paid.2008.09.020

Dadds, M. R., Hunter, K., Hawes, D. J., Frost, A. D. J., Vassallo, S., Bunn, P., ... \& El Masry, Y. (2008). A measure of cognitive and affective empathy in children using parent ratings. Child Psychiatry and Human Development, 39, 111-122. doi:10.1007/s10578-0070075-4

Davis, M. H. (1980). A multidimensional approach to individual differences in empathy. JSAS Catalog of Selected Documents in Psychology, 10, 85. Retrieved from http://www.uv.es/ friasnav/ Davis_1980.pdf

Davis, M. H., \& Franzoi, S., L. (1991). Stability and change in adolescent self-consciousness and empathy. Journal of Research in Personality, 25, 70-87. doi:10.1016/0092-6566(91)90006-C. ISSN: 0092-6566.

Decety, J. (2010). The neurodevelopment of empathy in humans. Developmental Neuroscience, 32, 257-267. doi:10.1159/ 000317771

Decety, J. (2011a). Dissecting the neural mechanisms mediating empathy. Emotion Review, 3, 92-108. doi:10.1177/1754073910374662

Decety, J. (2011b). The neuroevolution of empathy. Annals of the New York Academy of Sciences, 1231, 35-45. doi:10.1111/j.1749-6632. 2011.06027

Decety, J., \& Michalska, K. J. (2010). Neurodevelopmental changes in the circuits underlying empathy and sympathy from childhood to adulthood. Developmental Science, 13, 886-899. doi:10.1111/j. 1467-7687.2009.00940.x

Decety, J., \& Svetlova, M. (2012). Putting together phylogenetic and ontogenetic perspectives on empathy. Developmental Cognitive Neuroscience, 2, 1-24. doi:10.1016/j.dcn.2011.05.003

Eisenberg, N., Miller, P. A., Schaller, M., Fabes, R. A., Fultz, J., Shell, R., \& Shea, C. L. (1987). The role of sympathy and altruistic personality traits in helping: a reexamination. Journal of Personality, 57, 41-67. doi:10.1111/1467-6494.ep8972612

Eisenberg, N., \& Strayer, J. (1987). Empathy and its development. In N. Eisenberg \& J. Strayer (Eds.), Cambridge studies in social and emotional development (pp. 1-13). New York, NY: Cambridge University Press.

Feshbach, N. D., \& Roe, K. (1968). Empathy in six- and seven-year-olds. Child Development, 39, 133-145. doi:10.2307/1127365

Findlay, L. C., Girardi, A., \& Coplan, R. J. (2006). Links between empathy, social behavior, and social understanding in early childhood. Early Childhood Research Quarterly, 21, 347-359.

Gadermann, A. M., Guhn, M., \& Zumbo, B. D. (2012). Estimating ordinal reliability for Likert-type and ordinal item response data: A conceptual, empirical and practical guide. Practical Assessment, Research \& Evaluation, 17, 1-13.

Garaigordobil, M. (2009). A comparative analysis of empathy in childhood and adolescence: Gender differences and associated socioemotional variables. International Journal of Psychology and Psychological Therapy, 9, 217-235. 
Garton, A. F., \& Gringart, E. (2005). The development of a scale to measure empathy in 8- and 9-year old children. Australian Journal of Education and Developmental Psychology, 5, 17-25.

Geng, Y., Xia, D., \& Qin, B. (2012). The Basic Empathy Scale: A Chinese validation of a measure of empathy in children. Child Psychiatry and Human Development, 43, 499-510. doi:10.1007/ s105778-011-0278-6

Goodman, G. S., \& Quas, J. A. (2008). Repeated interviews and children's memory: It's more than just how many. Current Directions in Psychological Science, 17, 386-390. doi:10.1111/j.1467-8721. 2008.00611.x

Hatfield, E., Cacioppo, J. T., \& Rapson, R. L. (1993). Emotional contagion. Current Directions in Psychological Science, 2, 96-99. doi:10. 1111/1467-8721.ep10770953

Hoffmann, M. L. (2001). Gender segregation in childhood: A test of the interaction style theory. The Journal of Genetic Psychology: Research and Theory on Human Development, 162, 298-313.

Hughes, R., Tingle, B. A., \& Sawin, D. B. (1981). Development of empathic understanding in children. Child Development, 52, 122-128.

Humphries, M. L., Parker, B. L., \& Jagers, R. J. (2000). Predictors of moral reasoning among African American children: A preliminary study. Journal of Black Psychology, 26, 51-64. doi:10.1177/ 0095798400026001003

Iacoboni, M., \& Dapretto, M. (2006). The mirror neuron system and the consequences of its dysfunctions. Nature Review, 7, 942-951. doi: $10.1038 / \mathrm{nrn} 2024$

Jolliffe, D., \& Farrington, D. P. (2006). Development and validation of the Basic Empathy Scale. Journal of Adolescence, 29, 589-611. doi: 10.1016/j.adolescence.2005.08.010

Keulers, E. H. H., Evers, E. A. T. Stiers, P. \& Jolles, J. (2010). Age, sex, and pubertal phase influence mentalizing about emotions and actions in adolescents. Developmental Neuropsychology, 35, 555-569.

Knudson, K. H. M., \& Kagan, S. (1982). Differential development of empathy and prosocial behavior. Journal of Genetic Psychology, 140, 249-251.

Lam, C. B., Solmeyer, A. R., \& McHale, S. M. (2012). Sibling relationships and empathy across the transition to adolescence. Journal of Youth and Adolescence, 41, 1657-1670. doi:10.1037/t06349-000

Lamm, C., Batson, C. D., \& Decety, J. (2007). The neural substrate of human empathy: Effects of perspective-taking and cognitive appraisal. Journal of Cognitive Neuroscience, 19, 42-58. doi:10. 1162/jocn.2007.19.1.42

Li, C., Lv, R., Liu, J., \& Zhong, J. (2011). The adaptation of basic empathy scale among Chinese adolescents. Chinese Journal of Clinical Psychology, 19, 163-166.

Litvack-Miller, W., McDouglas, D., \& Romney, D. M. (1997). The structure of empathy during middle childhood and its relationship to prosocial behavior. Genetic, Social, and Psychology Monographs, 123, 303-324.

McCoy, C. L. \& Masters, J. C. (1985). The development of children's strategies for the social control of emotion. Child Development, 56, $1214-1222$

Mehrabian, A., \& Epstein, N. (1972). A measure of emotional empathy. Journal of Personality, 40, 525-543. doi:10.1111/1467-6494. ep8970028

Mestre, M. V., Samper, P., Frias, M. D., \& Tur, A. M. (2009). Are women more empathetic than men? A longitudinal study in adolescence.
The Spanish Journal of Psychology, 12, 76-83. doi:10.1037/ t01742-000

Munoz, L. C., Qualter, P., \& Padget, G. (2011). Empathy and bullying: Exploring the influence of callous-unemotional traits. Child Psychiatry and Human Development, 42, 183-196. doi:10.1007/ s10578-010-0206-1

Philpott, A. L., Rinehart, N. J., Gray, K. M., Howlin, P., \& Cornish, K. (2013). Understanding of mental states in later childhood: An investigation of theory of mind in autism spectrum disorder and typical development with a novel task. International Journal of Developmental Disabilities, 59, 108-117.

Reid, C., Davis, H., Horlin, C., Anderson, M., Baughman, N., \& Campbell, C. (2013). The Kids' Empathic Development Scale (KEDS): A multi-dimensional measure of empathy in primary school-aged children. British Journal of Developmental Psychology, 31, 231-256. doi:10.1111/bjdp.12002

Schonert-Reichl, K. A., Smith, V., Zaidman-Zait, A., \& Hertzman, C. (2012). Promoting children's prosocial behaviors in school: Impact of the "Roots of Empathy" program on the social and emotional competence of school-aged children. School Mental Health, 4, 1 21. doi: $10.1007 / \mathrm{s} 12310-011-9064-7$

Schwenck, C., Mergenthaler, J., Keller, K., Zech, J., Salehi, S., Taurines, R., ... \& Freitag, C. M. (2012). Empathy in children with autism and conduct disorder: Group-specific profiles and developmental aspects. Journal of Child Psychology and Psychiatry, 53, 651-569. doi:10.1111/j.1469-7610.2011.02499.x

Shamay-Tsoory, S. G. (2011). The neural bases for empathy. The Neuroscientist, 17, 18-24.

Strayer, J. (1993). Children's concordant emotions and cognitions in response to observed emotions. Child Development, 64, 188-201. doi: 10.1111/j.1467-8624.1993.tb02903.x

Surtees, A. D. R., \& Apperly, I. A. (2012). Egocentrism and automatic perspective taking in children and adults. Child Development, 83, 452-460. doi:10.1111/j.1467-8624.2011.01730.x

Van der Graaff, J., Branje, S., De Wied, M., Hawk, S., Van Lier, P., \& Meeus, W. (2014). Perspective taking and empathic concern in adolescence: Gender differences in developmental changes. Developmental Psychology, 50, 881-888. doi:10. 1037/t06349-000

Vetter, N. C., Altgassen, M., Phillips, L., Mahy, C. E. V. \& Kliegel, M. (2013). Development of affective theory of mind across adolescence: Disentangling the role of executive functions. Developmental Neuropsychology, 38, 114-125.

Wilcox, R. R. (2005). Introduction to robust estimation and hypothesis testing (2nd ed.). London: Elsevier.

Wu, S., Zhou, Z., Wei, H., \& Bao, N. (2013). Gender segregation and loneliness related in middle childhood. Chinese Journal of Clinical Psychology, 21, 479-482. doi:10.1037/t16291-000

Yeo, L., Ang, R., Loh, S., Fu, K. J., \& Karre, J. (2011). The role of affective and cognitive empathy in physical, verbal, and indirect aggression of a Singaporean sample of boys. Journal of Psychology: Interdisciplinary and Applied, 145, 313-330. doi:10. 1080/00223980.2011.568986

Zimmer-Gembeck, M. J., \& Skinner, E. A. (2011). The development of coping across childhood and adolescence: An integrative review and critique of research. International Journal of Behavioral Development, 35, 1-17. 